\title{
Design of Lake Ecological Observation Data Management
}

\author{
Bu Young Ahn, Young Jin Jung, Myung Sun Lee \\ Supercomputing Center \\ Korea Institute of Science and Technology Information, Daejeon, 305-806, Korea \\ Choong-Kyo Jeong, Bomchul Kim \\ Kangwon National University, 200-701, Korea
}

\begin{abstract}
To protect water pollution and scarcity in lake and river, water quality monitoring applications have become important tools to understand the change of aquatic ecosystem. KLEON (Korean Lake Ecological Observatory Network) is designed to manage and share the ecological observations. The various kinds of water quality and phytoplankton observations are collected from the selected observatories such as seven lakes/rivers/wetlands. To deeply understand the collected observations with weather, KLEON also manages the observatory information such as lake, dam, floodgate, and weather. The accumulated observation and analyzed results are used to improve the water quality index of the observatories and encourage the ecologists' cooperation.
\end{abstract}

Keywords: Water quality monitoring system, Lake ecological observation management, Lake observation network. Aquatic ecosystem assessment, Observatory information management.

\section{INTRODUCTION}

Water quality monitoring system is required to understand aquatic ecosystem health with high frequent observations. For example, it is hard for ecologists to understand the change of water quality with fragmented and irregular observation, because water quality is spatiotemporally changed by a variety of factors such as weather, climate, and geometry.

The trend of ecological observation is changed with the advance of sensor and wireless communication technology. For example, observation range definitely widened and an amount of data rapidly increased. An observation management tool is also required for ecologists to collect, share and analyze the increased various kinds of lake ecological observation.

To support the observation management tool, we designed KLEON (Korean Lake Ecological Observation Network), which is designed for ecologists to manage and share their observations by providing observation database, graph, and map service. KLEON handles 34 types of sampling observations and 5 types of sensor observations, which are collected from the selected observatories (lakes: Soyang, Euiam, and Youngrang; rivers: Soyang and Han; wetland: Upo; stream: Anyang, Gapyeong). To clearly understand observations, KLEON also manages the observatories such as lakes, sites, dams, floodgates, and sensors. To analyze the

This is an excellent paper selected from the papers presented at ICCC 2010.

*Corresponding author. E-mail : yjjung@kisti.re.kr

Manuscript received Feb.25, 2010 ; accepted Mar.20, 2011 various phenomena of lakes as shown in table 2, we installed sensors at the observatories. Through CDMA model and regular download, the observations are transmitted to KLEON server, which handles observations with dynamic data model and provides them on the internet to share the observations. The collected observations are used to improve the accuracy of water quality index of lakes and rivers by using water quality model such as CE-QUAL-W2 [1]. With KLEON, the analyzed results are used to encourage the ecological research community, the environment preservation service, and education.

\section{RELATED WORK}

In order to preserve and utilized aquatic ecological environment, water quality monitoring systems are developed ecumenically. Automatic water quality monitoring system is installed and operated by Ministry of Environment, K-water, Rural community cooperation, and Rural Research Institute.

MOE (Ministry of Environment) [2] manages AWQMS (Automatic water quality monitoring system) at 56 sites of four rivers such as Han, Gum, Nakdong, and Youngsan rivers. 19 water quality parameters are monitored in AWQMS. K-water (Korea Water Resources Cooperation) [3] developed RTMMS (Real-time Turbidity Monitoring and Management System) to manage the water quality at rivers and watershed. Water quality simulation model, CE-QUAL-W2 (2D) [1], is employed to understand the change of water quality. This RTMMS is used to protect natural disaster such as water scarcity and water 
pollution. For example, RTMMS predicted the flood at 2004 and 2006.

KORDI (Korea Ocean Research \& Development Institute) [4] installed the water quality monitoring stations in Lake Saemankum to collect nice water quality parameters such as temperature, $\mathrm{pH}$, dissolved oxygen, and turbidity. The parameters are transmitted to monitoring center in real time by using CDMA modem. KFRI (Korean Fisheries Research Institute) is operating water quality monitoring sensor network with 30 buoys at coast.

Center for Applied Aquatic Ecology, North Carolina State University [5] installed 10 RTRM (Real-time remote monitoring systems) at 18 sites, which is important to find the reasons of aquatic ecosystem problem such as fish kill, oxygen depletion, and harmful algal blooming as shown in Fig 1.

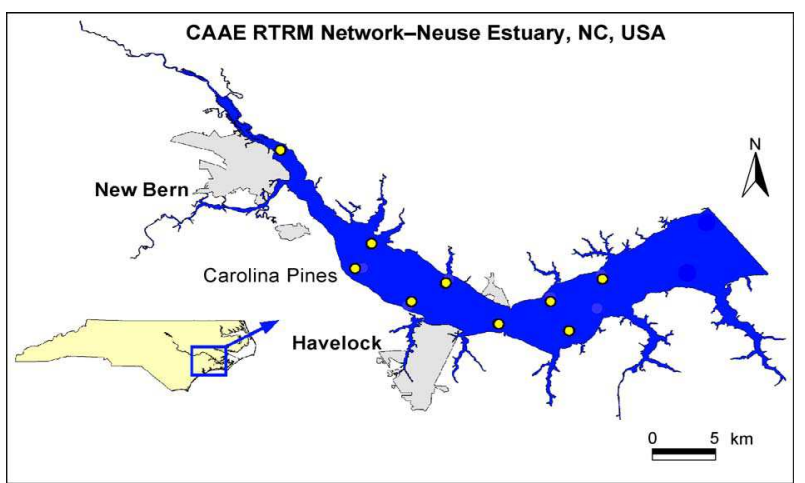

Fig. 1. Monitoring sites of the Neuse Estuary Monitoring and Research Program [5]

This RTRM platform is also used to monitor the behavior of fishes depending on the frequent change of water quality at Chesapeake Bay. FMRI (MARVIN-Florida Marine Research Institute) made the tool to automatically collect water quality. Various kinds of sensors are used to record the biological, physical, chemical, and meteorological data.

In Fig 2, at coast of Hong Kong, HARS (Harmful Algal Blooms) [6] are big problem to damage the ecosystem. For example, a number of fishes are killed at Hong Kong at 1998.

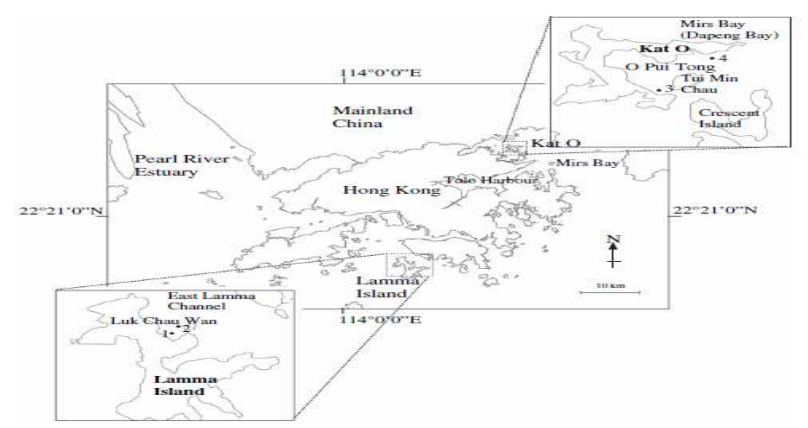

Fig. 2. Water quality monitoring sites in Hong Kong [6]

The water quality monitoring system, which is installed to protect this problem, gave 19 alarms about algal bloom from 2000 to 2003. This system checks chlorophyll and dissolved oxygen to find algal bloom. ORASNCO (Ohio River Valley Water Sanitation Commission) [7] is installed at 1948 to protect the industrial pollutant such as VOCs (Volatile Organic Compounds). Benzene pollution is found by monitoring system at 2003. They monitor the flow of benzene and give an alarm to protect the pollution. GLEON (Global Lake Ecological Observatory Network) [8] has a goal to understand and forecast the natural and artificial change of ecosystem in lake and reservoir. The members of GLEON installed buoys at lakes, which attach the different kinds of sensors to detect water quality.

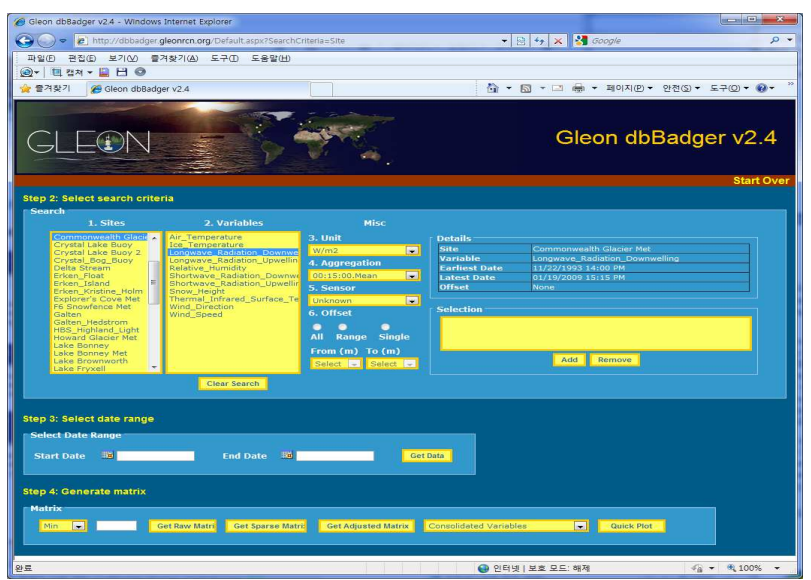

Fig. 3. Gleon dbBadger to share observations [8]

In GLEON website, users can check and analyze the past and the current sensor data at observation sites in the world by using the dbBadger, the VADER, and the lake analyzer as shown in Fig 3. GLEON is collecting high frequency data such as temperature, dissolved oxygen, dissolved carbon dioxide, plytoplankton pigments, acoustic Doppler current profilers, solar radiation, wind speed, and relative humidity. With this network, ecologists, geologists, scientists, and engineers share their observations and knowledge and develop new technologies and new models. For example, they try to understand the change of lake ecosystem depending on climate change.

GoMOOS (Gulf of Maine Ocean Observing System) [9] has been developed to understand and forecast the change of ocean, which strongly affects various ecosystems on the side of science, environment, commerce, and resource. The accumulated observation is used to guide ships (sailor), keep resource (ocean resource manager), forecast the climate change (scientist), give information (educator), rescue people (rescue team), and prevent ocean (public official). When a user searches the historical and the current observations, GoMOOS supplies graphing and download service through defining data type, time periods and locations. GoMOOS also provides the forecasting map such as wind and waves, marine forecast, water level, circulation, and right whale births.

LERNZ (Lake Ecosystem Restoration New Zealand) [10] is a site to restore lake ecosystem by constructing human network with the analyzed data and result. LERNZ focuses on restoring a variety of species by developing new models and technologies to effectively manage harmful algal blooms, new pest fish management and control technologies, city retrofit model. The installed buoys transmit their observations such as water column, $\mathrm{pH}$, light absorption and bottom nitrate 
concentration, dissolved oxygen, and chlorophyll fluorescence, phycocyanin (indicative of phytoplankton and cyanobacteria biomass respectively).

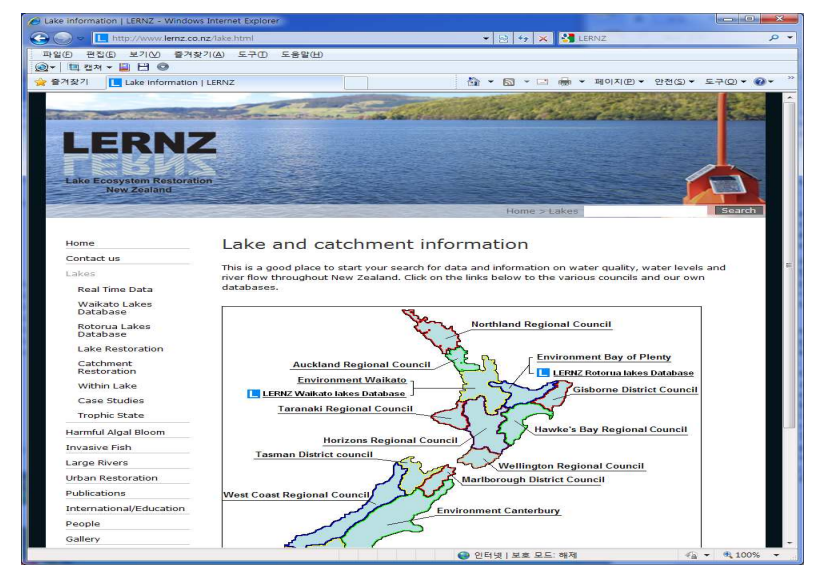

Fig. 4. The lake information of LERNZ [10]

To protect and restore lake ecosystem, they have several programs such as invasive fish research programme, large river ecology (large river research programme, developing large river sampling methodologies, measuring the effects of various human activities, developing approaches for ecological monitoring, testing indicators of large river ecological condition, understanding energy pathways fuelling fish nutrition, evaluating the effectiveness of restoration approaches; and developing models of large river ecosystems, urban restoration research).

LakeESP (Environmental Sensing Platform) [11] is developed by PME (Precision Measurement Engineering), which provides the particular sensors, software, and tools to support the fresh ocean water research. With international scientist community, PME develops the sensors, which are used to closely measure pressure, dissolved oxygen, and temperature. LakeESP consists of data logger, T-Chain (temperature, DO, PAR, pressure), station main frame, meteorology sensors, and data transmission. The sensors, which are installed on LakeESP transmit raw file to include the observations. The data stream is stored at raw file storage and transmitted user's pc by using FTP transfer.

Wetland is very important ecosystem, which is affected by water. Weland is useful to keep water quality, provide habitats for birds, and supply food. However, human destroys this wetland by changing the water flows, taking resources, and polluting wetland. Pakistan wetlands program [12], which includes marsh, fen, peatland or water has some is preventing the valuable wetlands with training such as learning wetland, being conservationist, and avoiding use of chemicals.

\section{ECOLOGICAL OBSERVATION PROCESSING}

To assess aquatic ecosystem health, ecologists need to share and analyze the observations in lakes and reservoirs. With the advance of sensor and wireless communication technology, the trend of the collected ecological observation is changed as below table.
Table 1. The change of observation trend

\begin{tabular}{|c|c|}
\hline Items & Observation trend \\
\hline Temporal variability & low $\rightarrow$ high \\
\hline Spatial resolution & low $\rightarrow$ high \\
\hline Observation range & small $\rightarrow$ wide \\
\hline
\end{tabular}

With this change of trend of Table 1, an amount of observations rapidly increase. Limnologists and ecologists need the data acquisition and management tool to handle these increased observations. In order to support ecologists' requirement, KLEON, which supports ecological research environment, is designed to share the ecological observations and the observatory such as weather, lake, dam, and flood gate.

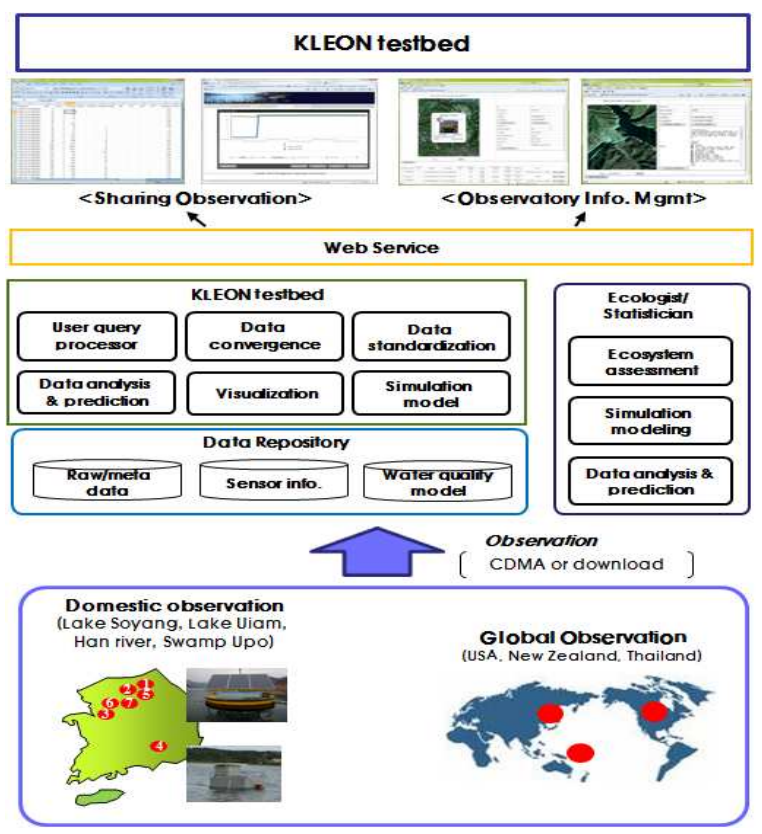

Fig. 5. KLEON structure

KLEON consists of the user query processor, data convergence, data standardization, data analysis \& prediction, visualization, and simulation model as shown in Fig 5. KLEON handles water quality and plankton data, the information of sensor, lake, dam, and weather.

Seven observation sites are selected to analyze water quality as shown in table 2 . The installed buoys transmit sensor data such as water temperature, dissolved oxygen, electronic conductivity, and turbidity. With the sensorML of OGC [1315], the status and history of the installed sensors are stored in KLEON. Users manage the received observations with observatory information by using a map service on the internet. Ecologists analyze the phenomenon by using the accumulated data with water quality model such as CE-QUAL-W2. Besides, the accuracy of water quality indices at seven sites will be improved with the accumulated observation data.

\subsection{Observatory network}

To evaluate eutrophication, turbid water, and analysis of causes of fish kill by Oxygen deficit, we installed five kinds of sensors at seven observation sites such as lakes, rivers, and 
wetlands as shown in Fig 6.

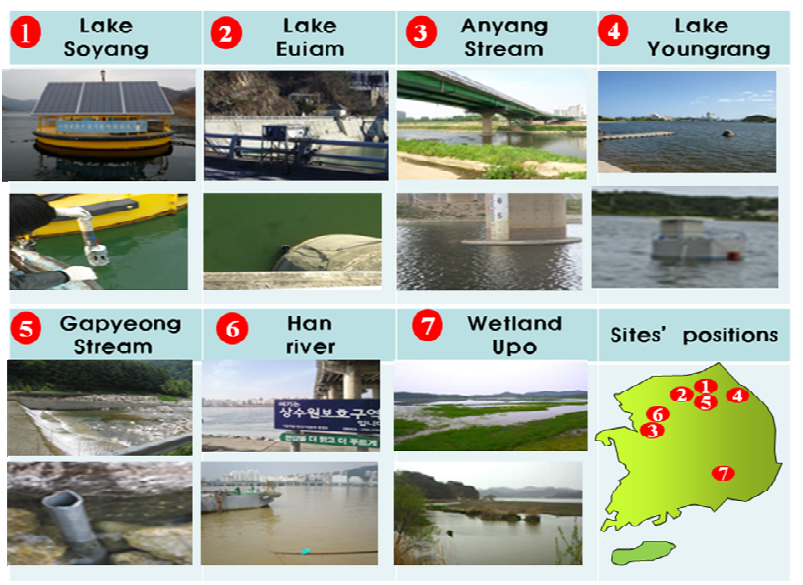

Fig. 6. KLEON observatories

Table 2. The installed sensor types at observatories

\begin{tabular}{|c|c|l|l|}
\hline \multicolumn{2}{|c|}{ Site } & Sensor types & \multicolumn{1}{c|}{ Analysis } \\
\hline 1 & $\begin{array}{c}\text { Lake } \\
\text { Soyang }\end{array}$ & Temp., DO, EC & $\begin{array}{l}\text { Eutrophication } \\
\text { Turbid water }\end{array}$ \\
\hline 2 & $\begin{array}{c}\text { Lake } \\
\text { Euiam }\end{array}$ & $\begin{array}{l}\text { Temp., EC, } \\
\text { Turbidity }\end{array}$ & $\begin{array}{l}\text { Eutrophication } \\
\text { Turbid water }\end{array}$ \\
\hline 3 & $\begin{array}{c}\text { Anyang } \\
\text { Stream } \\
\text { Youngrang }\end{array}$ & $\begin{array}{l}\text { Temp., DO, EC, } \\
\text { pH, turbidity }\end{array}$ & $\begin{array}{l}\text { fish kill } \\
\text { (oxygen deficit) }\end{array}$ \\
\hline 5 & $\begin{array}{c}\text { Gapyeong } \\
\text { Stream }\end{array}$ & Temp., EC & $\begin{array}{l}\text { fong-term ecological research } \\
\text { (oxygen deficit) }\end{array}$ \\
\hline 6 & $\begin{array}{c}\text { Han } \\
\text { River }\end{array}$ & Temp., EC & $\begin{array}{l}\text { Long-term ecological research } \\
\text { climate change }\end{array}$ \\
\hline 7 & $\begin{array}{c}\text { Wetland } \\
\text { Upo }\end{array}$ & Temp., DO, EC & $\begin{array}{l}\text { Long-term ecological research } \\
\text { Eutrophication }\end{array}$ \\
\hline
\end{tabular}

The detailed sensor types and the analysis goal are described in table 2. To provide this sensor information to users, KLEON employs the sensorML of OGC as the standardization to describe the sensor's properties.

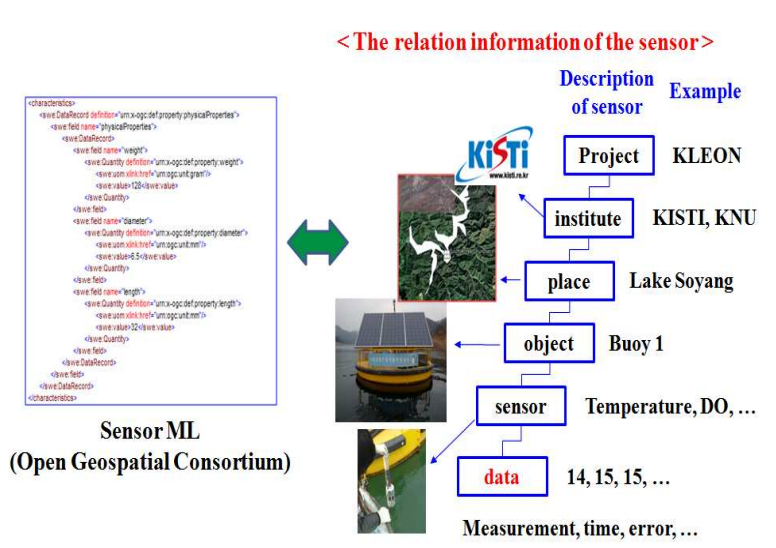

Fig. 7 Description of sensors

In Fig 7, SensorML describes the installed sensors' properties such as model no. name, accuracy, sampling interval, and error rate. This information is used to understand the status of sensors with error rate and sampling interval.

\section{2 observation transmission}

Fig 8 shows the overall observation transmission. When the installed sensors observe the environmental condition, the observation is transmitted to data collector in a server through CDMA modem. The collected observations are stored in database by using VEGA model [16], which is designed in GLEON [8]. Users can search and download observations on KLEON web site.

Table 3. Observation and observatory in KLEON

\begin{tabular}{|c|c|c|c|}
\hline \multicolumn{3}{|c|}{ Items } & Types \\
\hline \multirow{3}{*}{ Observations } & \multirow{2}{*}{$\begin{array}{l}\text { Sampling } \\
\text { data }\end{array}$} & Water quality & 34 types (Turbid, SS, VSS, NVSS, BOD, COD, ... ) \\
\hline & & Plankton & plant plankton (Cyanobacteria, Chlorophyceae, ... ) \\
\hline & $\begin{array}{c}\text { Sensor } \\
\text { data }\end{array}$ & Water quality & temp. $\mathrm{pH}$, electrical conductivity, water temperature, dissolved oxygen, turbidity \\
\hline \multirow{6}{*}{ Observatory } & $\begin{array}{l}\text { Sensor } \\
\text { Information }\end{array}$ & Sensor & SensorML (model no. name, position, sampling interval, ...) \\
\hline & \multirow{5}{*}{$\begin{array}{l}\text { Observatory } \\
\text { Information }\end{array}$} & Dam & general, reservoir, spill way, tailrace, power plant, note \\
\hline & & Floodgate & $\begin{array}{l}\text { date, water level, inflow rate, total outflow rate, power generation outflow rate, extra } \\
\text { outflow rate }\end{array}$ \\
\hline & & Lake & extent, maximum length \\
\hline & & Site & site ID, source, position, project, period \\
\hline & & Weather & temperature, cloud, solar radiation, wind speed and direction \\
\hline
\end{tabular}




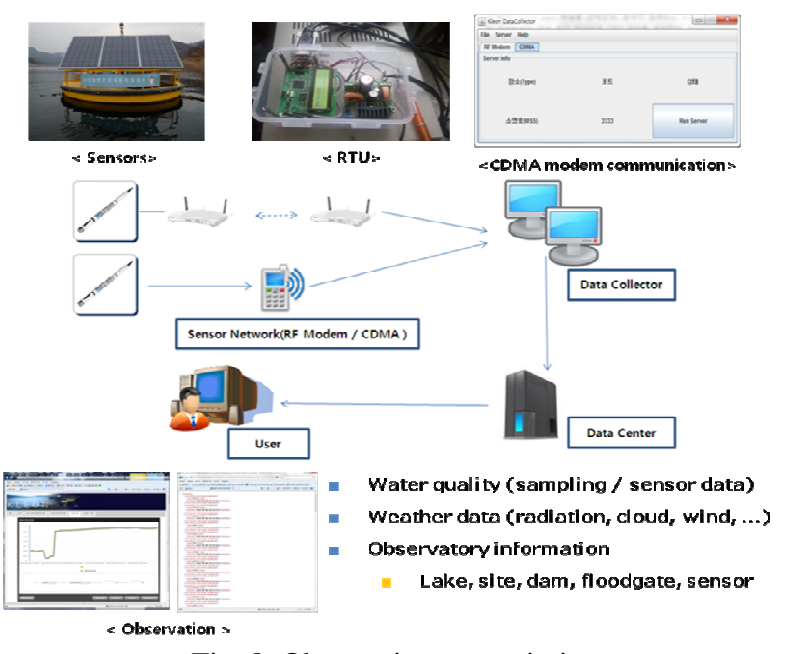

Fig. 8. Observation transmission

Fig 9 shows the collected observation. The observations are analyzed by using water quality model with the relation between observation and observatory information such as weather and construction.

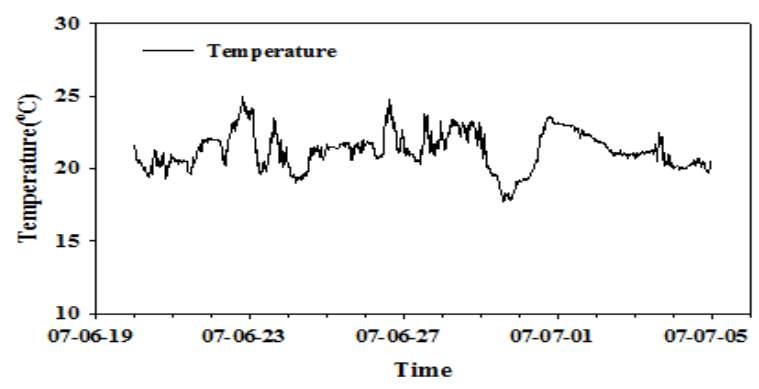

Fig. 9. The collected observation

\section{3 observation database}

In order to support the ecologist's research, KLEON handles not only sensor and sampling observations but also the information of sensor, weather, lake, dam, and floodgate.

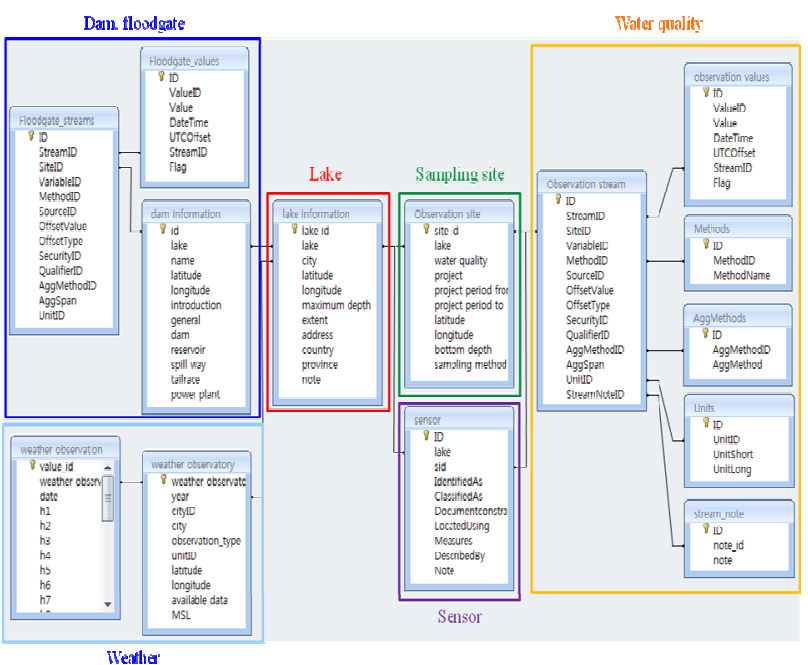

Fig 10. Design of observation database
To store the observation and the observatory information which is shown in Table 3 [17], the observation database is designed to describe the relation among lake, site, observations, and observatories. A lake has several sites depending on observations such as dissolved oxygen, temperature, and $\mathrm{pH}$. A site has additional observatory information, there are relations among a lake, a dam, a floodgate and weather.

Lake tables store the lake information such as lake's name, latitude, longitude, maximum depth, and extent. Observation site, which is the sampling point, is included in lake. Weather tables store six kinds of weather data such as solar radiation, total cloud cover, air temperature, dew point temperature, wind direction, and wind speed. Weather data is provided by KMA (Korea Meteorological Administration). Water quality table stores 42 attributes of the sampling data such as water temperature, $\mathrm{pH}$, turbidity, BOD, COD, and DIP. Phytoplankton describes the extracted plankton from sampling water. This sampling data has different kinds of attributes to indicate the water quality. This data is very useful to understand the change of ecosystem in lake.

To detect the phenomenon, sensor observation is also important, because sensors continuously check the water quality for every sampling interval. More sensors will be installed to observe the change of ecosystem in lake. To handle the sensor data, we extend the Vega [16], which is designed to handle sensor observation at GLEON. These tables are designed for ecologists to manage and analyze the observation and the related information with web interface.

\section{OBSERVATION MANAGEMENT ON THE WEB}

To provide the sensor and the sampling observations and the information of lake, dam, floodgate, and weather, we designed the google earth based user interface. Fig 11 shows the web service of KLEON.

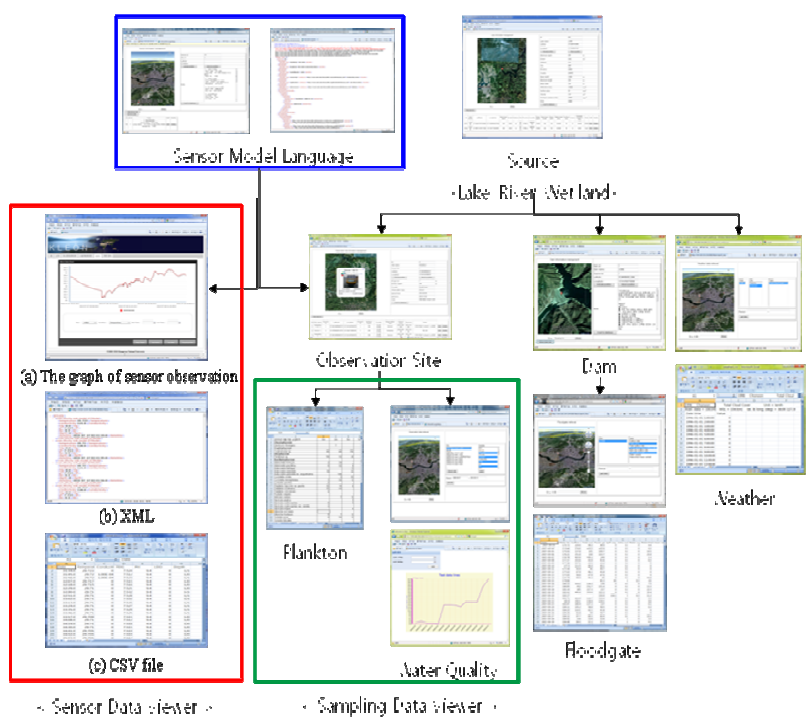

Fig. 11. Overview of KLEON web service

In order to estimate the water quality of sites, users can search observations through sensor data viewer and sampling data 
viewer. To clearly understand the change of water quality, observatory information is also managed on the web. To show the sensor data at seven lakes, reservoirs, or wetland on the web with the geographical information, the google earth based user interface is provided as shown in Fig 12. For example, users can find lakes (a) in the world with google earth. When users click the sensor mark (b), which are attached on a buoy or a bridge in the selected lake, the sensor description and the observation data in the sensor mark is provided.
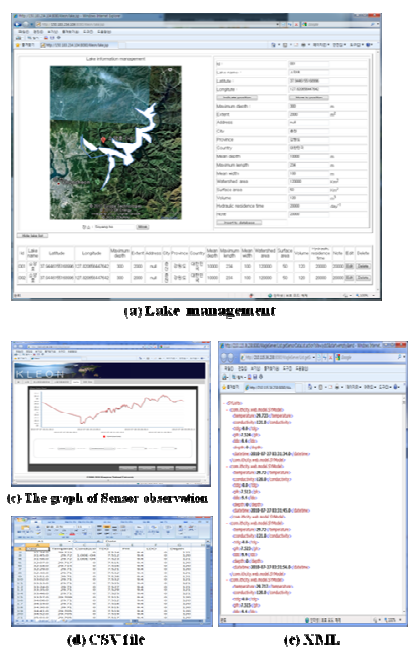

(d) Cst rile (e) XnII

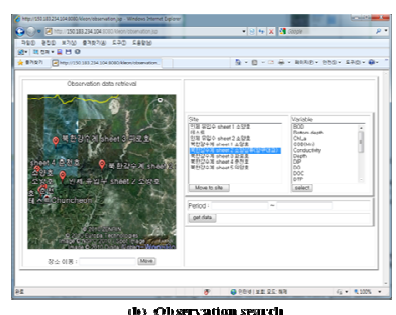

(b) Ouservanion searcil

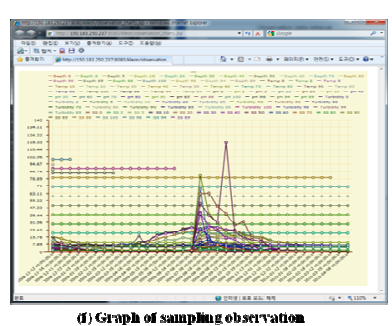

Fig 12. Google earth based user interface and observation search

The observed sampling and sensor data is presented in graph, $\mathrm{xml}$, and CSV (Comma-separated values) file. For example, the observation at Soyang river is shown as the graph of sensor data (c), CSV (d), xml (e), and the graph of sampling data (f). With these kinds of data forms, ecologists share their observations and discuss their research.

\section{OBSERVATION ANALYSIS}

Ecologist analyzes the accumulated observations of KLEON by using a water quality model. For example, CE- QUAL-W2 (two-dimensional water quality and hydrodynamic code) is used to represent the water quality of Lake Soyang.

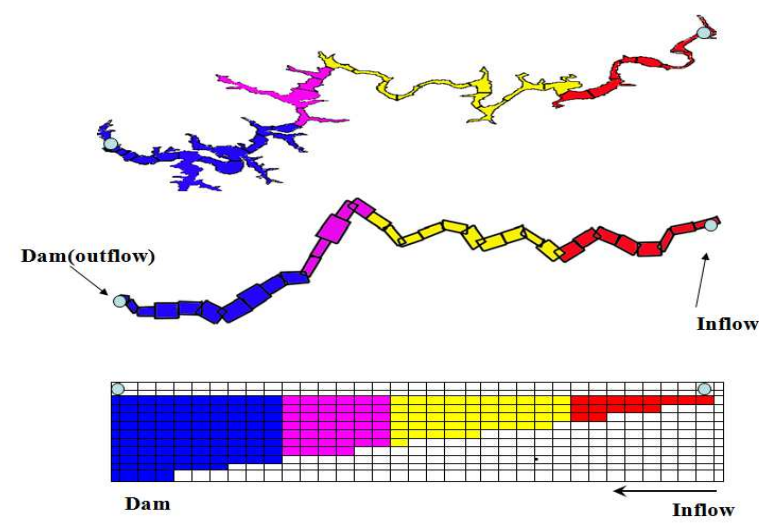

Fig. 13. Grid of water quality model (CE-QUAL-W2) for observation analysis in Lake Soyang
In Fig 13, the grid, which includes 4 sections (blue, pink, yellow, red), shows the gradient of depths of Lake Soyang. Each section includes horizontal segments and a segment is also divided to vertical cells. In each cell, several equations are used to calculate the represented value. When ecologists put their observations to the model, it makes the analyzed and the predicted the results. By comparing the different kinds of observations with water quality model (CE-QUAL-W2), ecologists try to understand the change of ecosystem in lake. For example, researchers at Kangwon national university analyze the cause of fish kill at Anyang stream with the observation. They tried to find the oxygen exhaustion points, which can make the fish kill by comparing temperature, dissolved oxygen, turbidity, and conductivity.

\section{CONCLUSION}

KLEON is designed to support ecologists' research by managing the observations and the observatory information. As a result, the accuracy of water quality index of the selected observation site is improved with the accumulated observation by utilizing CE-QUAL-W2. The accumulated observations and analyzed results will be used to support ecological science, IT, community, and national policy. KLEON also encourages global ecological research cooperation by sharing its observation data and supporting IT with GLEON.

\section{REFERENCES}

[1] Water quality and hydrodynamic model, http://www.ce.pdx.edu/w2/

[2] Ministry of Environment, http://www.me.go.kr

[3] Korea water resource corporation, http://www.kwater.or.kr/

[4] Korea Ocean Research\&Development Institute, http://www.kordi.re.kr

[5] Center for Applied Aquatic Ecology, North Carolina State University, http://www.ncsu.edu/wq/

[6] S. Lu, I. J. Hodgkiss1, "Harmful algal bloom causative collected from Hong Kong waters," Hydrobiologia, Vol. 512, No. 1-3, 2004, pp. 231-238.

[7] ORASNCO (Ohio River Valley Water Sanitation Commission), http://www.orsanco.org/

[8] Global Lake Ecological Observatory Network, http://gleon.org

[9] GoMOOS (Gulf of Maine Ocean Observing System), http://www.gomoos.org/

[10] LERNZ Lake Ecosystem Restoration (New zealand), http://www.lernz.co.nz/

[11] LakeESP (PME USA), http://www.pme.com/

[12] Wetlands Programme (Pakistan), http://www.pakistanwetlands.org/

[13] OGC (Open Geospatial Consortium), http://www.opengeospatial.org/

[14] Sensoer Web Enablement of Open GIS consortium, http://www.opengeospatial.org/projects/groups/sensorweb

[15] A. Sheth, C. Henson, and S. Sahoo, "Semantic Sensor 
Web," IEEE Internet Computing, July/August 2008, pp.78-83.

[16] L. A. Winslow, B. J. Benson, K. E. Chiu, P. C. Hanson, and T. K. Kratz, "Vega: a flexible data model for environmental time series data," Proceedings of the Environmental Information Management Conference 2008, pp. 166-171,. Albuquerque, NM September 10-11, 2008.

[17] B. Y. Ahn, Y. J. Jung, C. K. Jeong, B. Kim, K. W. Cho, Ecological Observation Viewer for Monitoring Lake Ecosystem, PRAGMA 19, 2010.

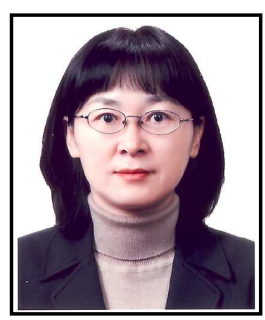

\section{Bu Young Ahn}

She is senior researcher at the Supercomputing Center, Korea Institute of Science and Technology Information (KISTI), where she does research on eScience, metadata, and factual data. She finished her Ph.D. thesis at the University of Chungnam under professors Eungbong Lee on the Open Community Framework Development based on Web 2.0.

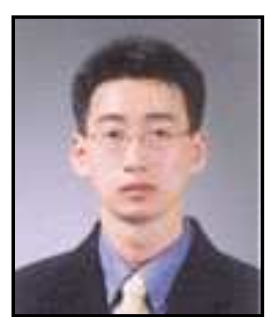

Young Jin Jung

$\mathrm{He}$ is senior researcher at the Supercomputing Center, Korea Institute of Science and Technology Information (KISTI). He got his Ph.D. degree in computer science from Chungbuk National University, South Korea, in 2007. He worked as a research scholar at University of Maine from October 2007 to January 2010. His research interests include spatiotemporal database application, moving object index, sensor data processing, and environmental monitoring application.

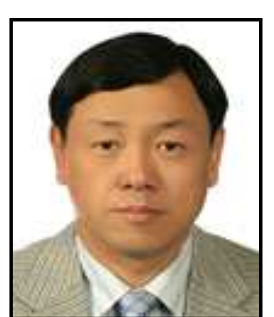

\section{Myung Sun Lee}

$\mathrm{He}$ is principal researcher at the Supercomputing Center, Korea Institute of Science and Technology Information (KISTI), where he does research on data processing, network security, and information system security. He finished his Ph.D. thesis at the University of

Hannam under professors Jeakwang Lee.

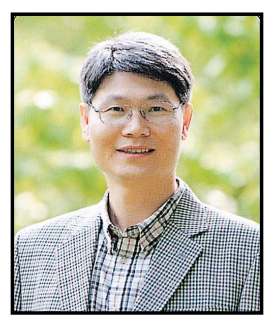

\section{Choong-Kyo Jeong}

$\mathrm{He}$ is a professor at Dept. of Computer and Communications Engineering, College of Information Technology, Kangwon National University, where he does research on internet and overlay networks, and wireless/mobile network protocols and applications. He finished his Ph.D. at Korea Advanced Institute of Science and Technology.

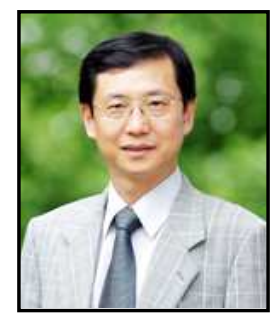

\section{Bomchul Kim}

$\mathrm{He}$ is a professor at Dept. of Environmental Science, Kangwon National University, where he does research on lake water quality management, lake aquatic ecology, and the relationship between climate change and water quality. He finished his Ph.D. at Seoul National University. 